\title{
Adolescent Sexual Behavior and Reproductive Outcomes In Central America: Trends over the Past Two Decades
}

By Ghazaleh Samandariand llene S.Speizer

Ghazaleh Samandari is a doctoral candidate, and Ilene S. Speizer is research associate professor, both in the Department of Maternal and Child Health, Gillings School of Global Public Health, University of North Carolina at Chapel Hill, Chapel Hill, NC, USA.
CONTEXT: Compared with the Latin American average, adolescent fertility is high in El Salvador, Guatemala, Honduras and Nicaragua, countries that also have high poverty levels and poor access to reproductive health care.

METHODS: For each country, data were drawn from four national health surveys conducted between 1987 and 2007, and analysis focused on trends in sexual and reproductive behavior among adolescent females aged 15-19. Event history analysis examined transitions to first sexual intercourse, first union and first live birth across survey years; Cox hazard and logistic regression analyses assessed associations between selected demographic characteristics and these outcomes, as well as ever-use of a modern contraceptive method.

RESULTS: The likelihood that adolescent females have initiated sexual intercourse has increased over time in EI Salvador, Honduras and Nicaragua, and has remained stable in Guatemala. Meanwhile, the odds of having entered their first union have declined in Nicaragua and risen in El Salvador, but have not changed in Honduras or Guatemala. Notably, the likelihood that adolescents have ever used a modern contraceptive method has increased in all four countries over the survey years. Nicaraguan adolescents became significantly less likely to have had their first live birth over the study period. Finally, urban residence, education level and socioeconomic status were important predictors of adolescents'sexual and reproductive outcomes.

CONCLUSIONS: Programmatic and policy initiatives should focus on improving adolescents'education and socioeconomic prospects, and efforts are especially needed to help adolescents delay the age at which they become sexually active and enter their first union.

International Perspectives on Sexual and Reproductive Health, 2010, 36(1):26-35
Despite recent global declines in the rate of early childbearing, adolescent childbearing is a persistent challenge in many countries. Early motherhood is widely recognized as having negative consequences for the health of the young woman and her infant, as well as for their future economic, educational and social prospects. ${ }^{1-4}$ These risks are particularly important in regions such as Central America, where poverty levels are high and access to resources is low. ${ }^{5-7}$

Compared with older mothers, adolescent mothers are at an increased risk of pregnancy-related complications; maternal mortality among adolescents aged 15-19 is twice as high as that among older women. ${ }^{8-11}$ Each year, 2.5 million adolescents worldwide undergo unsafe abortions, which put them at additional risk of adverse outcomes. ${ }^{12-14}$ In addition to these physical health risks, adolescent mothers attain lower levels of education, have fewer economic opportunities and experience higher rates of poverty, ${ }^{2-4,15}$ and their children are at increased risk of neonatal mortality, preterm birth, low birth weight and developmental delays. ${ }^{16-21}$ Furthermore, the children of adolescent mothers are more likely to suffer neglect and malnutrition, often due to the poorer social and economic status of their mothers. ${ }^{22,23}$ Such children also face elevated risks of low educational attainment and of teenage parenthood. ${ }^{24-26}$

Adolescent fertility is high in Central America: The lat- est national health surveys from 2002-2007 indicate that fertility rates for 15-19-year-olds are 137 births per 1,000 women in Honduras, 119 in Nicaragua, 114 in Guatemala and 104 in El Salvador, while the Latin American average is 75 births per 1,000 women aged 15-19. ${ }^{27-31}$ Although these four countries have experienced modest declines in total fertility rates over the last two decades, the rate of childbearing among adolescents remains extremely high. The already low levels of socioeconomic status and health care accessibility among these populations are further exacerbated by early childbearing.

According to a recent assessment of the UN Millennium Development Goals in Latin America, El Salvador, Guatemala, Honduras and Nicaragua are far from achieving their goals of reducing maternal and infant mortality. ${ }^{32}$ Maternal mortality ranges from 170 deaths per 1,000 women in El Salvador and Nicaragua to 280-290 deaths per 1,000 women in Honduras and Guatemala. ${ }^{31}$ These numbers have changed little in recent years, and evidence suggests that maternal mortality ratios are persistently higher among adolescents than among adult women. ${ }^{8}$ Infant mortality in Guatemala and Honduras also remains elevated in relation to Latin America overall, despite declines over the past decade (30 and 28 deaths, respectively, per 1,000 live births vs. 22 deaths per 1,000 live 
births). ${ }^{33}$ High infant mortality rates are associated with poverty and low educational attainment, factors for which adolescent mothers are at increased risk. ${ }^{34,35}$ Indeed, a UN report argues that "It will be impossible to attain the Millennium Development Goals related to maternal health unless resources are invested and effective action taken among the adolescent and youth population." 32

To address reproductive health issues among adolescents in Central America, the trends and causes of sexual and childbearing behaviors must be understood. To date, no study has specifically examined and compared longterm trends in adolescent sexual and reproductive behavior in El Salvador, Guatemala, Honduras and Nicaragua. This analysis uses data from multiple time points for each country over the past two decades to describe trends in sexual experience, union status, contraceptive use and childbearing among women aged 15-19. The analysis also assesses whether selected demographic and socioeconomic factors are associated with trends in sexual activity and childbearing in these countries.

\section{METHODS}

This study examines data collected between 1987 and 2007 from four nationally representative surveys each for El Salvador, Guatemala, Honduras and Nicaragua. These surveys are either Demographic and Health Surveys conducted by Macro International, or national surveys carried out with technical assistance from the U.S. Centers for Disease Control and Prevention, Management Sciences for Health or Family Health International (Table 1).

All surveys used a two-stage, stratified cluster design; the first stage was a selection of primary sampling units from a census or other nationwide sampling frame, with probability proportional to size, and the second stage was a random selection of 20-30 households within each selected unit. Each survey was representative at the national and provincial levels, as well as by urban versus rural stratification. Once a household was selected for a given survey, all eligible women from the household were chosen for participation; to be eligible, women had to be 15-49 and give their consent. This study considers only respondents who were 15-19 at the time of the survey. On average, this age-group constituted $20-25 \%$ of the total sample in any given year. Table 1 provides the unweighted number of women for each survey, as well as the unweighted number of those aged 15-19.

\section{Measures}

Women were interviewed in or around their homes and were asked questions related to their sexual and reproductive health behavior. The four main outcomes used in this analysis were: ever having had sexual intercourse; ever having been in a union (consensual or legal); ever having used a modern contraceptive (the pill, condom, IUD, injection, implant, or male or female sterilization); and ever having had a live birth. For the intercourse, union and live birth measures, the age at first experience was recorded for TABLE 1. Surveys used in the analysis of sexual and repro-
ductive health trends in EI Salvador, Guatemala, Honduras
and Nicaragua, by sample size

\begin{tabular}{lcc} 
Country and survey & $\begin{array}{c}\text { No. of women } \\
\text { aged } 15-49\end{array}$ & $\begin{array}{c}\text { No. of women } \\
\text { aged } 15-19\end{array}$ \\
\hline El Salvador & & \\
1988 FESAL & $3,579 \dagger$ & 753 \\
1993 FESAL & 6,207 & 1,157 \\
1998 FESAL & 12,634 & 2,297 \\
2002-2003 FESAL & 10,689 & 1,839 \\
& & \\
Guatemala & & \\
1987 DHS & $5,160 \dagger$ & 1,182 \\
1995 DHS & 12,403 & 2,949 \\
1998-1999 DHS & 6,021 & 1,403 \\
2002 ENSMI & 9,155 & 1,601 \\
& & \\
Honduras & & 1,884 \\
1991-1992 ENESF & $7,521 \dagger$ & 1,456 \\
1996 ENESF & 7,505 & 1,512 \\
2001 ENESF & 8,362 & 4,566 \\
2005-2006 DHS & 19,948 & \\
& & 1,251 \\
Nicaragua & & 3,357 \\
1992-1993 ENSSF & 7,150 & 3,146 \\
1998 DHS & 13,634 & \\
2001 DHS & 13,060 & \\
2006-2007 DHS & 14,221 & \\
\hline
\end{tabular}

tWomen aged 15-44. Notes: Ns are unweighted. FESAL=Encuesta Nacional de Salud Familiar. DHS=Demographic and Health Survey. ENSMI=Encuesta Nacional de Salud Materno Infantil.ENESF=Encuesta Nacional de Epidemiología y Salud Familiar. ENSSF=Encuesta Nacional Sobre Salud Familiar.

women who responded affirmatively to the question. Everuse of a modern contraceptive was selected over current use to maintain consistency with the other outcomes and to represent adolescents' general experience with methods. Although the surveys did not have identical questions for these four main measures, they collected similar data. In some cases, responses were recoded from multiple response options to create a binary outcome. For example, most surveys asked women about their experience with individual contraceptive methods, and responses were then collapsed and recoded.

Data on five demographic control variables were also used: age (in single years), area of residence (urban vs. rural), educational attainment, socioeconomic status and marital status. Educational attainment was categorized as no education, primary education (1-6 years), or secondary or higher education (seven or more years). A Filmer and Pritchett principal components analysis of household services was used to create an indicator of socioeconomic status for each survey. ${ }^{36}$ The surveys varied in their definition of services and availability of data for each asset, but all surveys included data on numerous assets and services. * After socioeconomic index scores were calculated, they were divided into quintiles, which were then collapsed into three categories: low (first and second quintiles), medium (third and fourth quintiles) and high (fifth quintile) socioeconomic status. ${ }^{37}$

*Variables included water source, toilet facilities; cooking source; presence of electricity; number of bedrooms; sanitation services; type of roof, wall and floor materials; and possession of various items (radio, TV, refrigerator, telephone or motor vehicle). 
TABLE 2. Percentage distribution of women aged 15-19, by selected demographic characteristics, according to country and survey year

\begin{tabular}{|c|c|c|c|c|c|c|c|c|c|c|c|c|c|c|c|c|}
\hline \multirow[t]{2}{*}{ Characteristic } & \multicolumn{4}{|c|}{ El Salvador } & \multicolumn{4}{|c|}{ Guatemala } & \multicolumn{4}{|c|}{ Honduras } & \multicolumn{4}{|c|}{ Nicaragua } \\
\hline & 1988 & 1993 & 1998 & $\begin{array}{l}2002- \\
2003\end{array}$ & 1987 & 1995 & $\begin{array}{l}1998- \\
1999\end{array}$ & 2002 & $\begin{array}{l}1991- \\
1992\end{array}$ & 1996 & 2001 & $\begin{array}{l}2005- \\
2006\end{array}$ & $\begin{array}{l}1992- \\
1993\end{array}$ & 1998 & 2001 & $\begin{array}{l}2006- \\
2007\end{array}$ \\
\hline \multicolumn{17}{|l|}{ Age } \\
\hline 15 & 20.3 & 20.4 & 18.7 & 18.1 & 19.7 & 20.3 & 21.4 & 24.8 & 21.6 & 22.4 & 20.0 & 22.3 & 17.7 & 20.4 & 19.8 & 21.7 \\
\hline 16 & 18.8 & 19.4 & 21.7 & 22.3 & 22.8 & 21.4 & 21.7 & 19.6 & 20.3 & 23.2 & 20.2 & 20.8 & 20.8 & 22.0 & 20.6 & 21.6 \\
\hline 17 & 21.9 & 19.5 & 19.2 & 21.3 & 23.4 & 22.4 & 19.4 & 19.4 & 20.1 & 19.1 & 20.8 & 20.4 & 21.7 & 21.3 & 20.4 & 19.7 \\
\hline 18 & 18.9 & 20.8 & 21.5 & 21.5 & 19.2 & 19.1 & 19.8 & 18.1 & 19.1 & 17.5 & 22.1 & 19.5 & 22.1 & 19.9 & 20.3 & 19.2 \\
\hline 19 & 20.1 & 20.0 & 19.0 & 16.8 & 14.9 & 16.8 & 17.6 & 18.1 & 19.0 & 17.8 & 16.9 & 17.0 & 17.7 & 16.4 & 18.9 & 17.8 \\
\hline \multicolumn{17}{|l|}{ Residence } \\
\hline Urban & 55.6 & 62.0 & 52.5 & 54.7 & 37.0 & 44.0 & 41.7 & 40.7 & 45.7 & 48.4 & 49.6 & 54.7 & 55.5 & 63.5 & 61.7 & 55.7 \\
\hline Rural & 44.4 & 38.0 & 47.5 & 45.3 & 63.0 & 56.0 & 58.3 & 59.3 & 54.3 & 51.6 & 50.4 & 45.3 & 44.5 & 36.5 & 38.3 & 44.3 \\
\hline \multicolumn{17}{|c|}{ Education level } \\
\hline None & 11.6 & 6.4 & 5.8 & 3.7 & 25.6 & 17.4 & 15.2 & 12.6 & 6.2 & 5.4 & 4.2 & 3.8 & 10.5 & 7.8 & 6.3 & 4.8 \\
\hline Primary & 41.4 & 40.0 & 37.8 & 29.3 & 53.3 & 50.1 & 49.1 & 50.4 & 66.4 & 65.5 & 60.3 & 47.4 & 46.5 & 41.4 & 40.1 & 37.0 \\
\hline$\geq$ secondary & 47.1 & 53.8 & 56.5 & 67.0 & 21.2 & 32.5 & 35.8 & 37.0 & 27.5 & 29.1 & 35.5 & 48.9 & 43.1 & 50.8 & 53.7 & 58.2 \\
\hline \multicolumn{17}{|c|}{ Socioeconomic statust } \\
\hline Low & 43.1 & 47.1 & 44.7 & 33.0 & 37.4 & 31.6 & 33.3 & 31.7 & 49.1 & 42.2 & 33.9 & 32.1 & 48.1 & 38.2 & 38.5 & 37.2 \\
\hline Medium & 34.2 & 39.4 & 33.0 & 37.4 & 35.2 & 42.8 & 41.4 & 47.6 & 27.1 & 36.9 & 39.1 & 45.2 & 34.8 & 44.9 & 44.5 & 39.7 \\
\hline High & 22.7 & 13.5 & 22.3 & 29.6 & 27.4 & 25.6 & 25.2 & 20.8 & 23.7 & 21.0 & 26.9 & 22.8 & 17.1 & 16.8 & 17.0 & 23.1 \\
\hline Total & 100.0 & 100.0 & 100.0 & 100.0 & 100.0 & 100.0 & 100.0 & 100.0 & 100.0 & 100.0 & 100.0 & 100.0 & 100.0 & 100.0 & 100.0 & 100.0 \\
\hline
\end{tabular}

†Socioeconomic status is based on a principal components analysis of household commodities; "low" represents the bottom two quintiles, "medium" the third and fourth quintiles, and "high" the top quintile. Note: Percentages may not total 100.0 because of rounding.

\section{Data Management and Analysis}

The four data sets for each country were combined, and variables were standardized across all data sets. Listwise deletion was used to remove cases that lacked complete data on all study variables. For Honduras, there was significant missing data on age at first sex for one survey, which reduced the sample size for this particular analysis.

The weighted percentages for each outcome variable were calculated for each survey year by country. Event history analysis was used to examine trends in transitions to first sex, first union and first live birth over the survey years; Cox hazard regression analyses were run separately for each country. For transition to first sex and first union, all women aged 15-19 were included in the analysis. For transition to first birth, the sample was restricted to those who reported ever having had sex. Trends in ever-use of a modern contraceptive were examined using multivariate logistic regression, and included only women who had had sex. All analyses controlled for age, area of residence, education level, socioeconomic status and survey year. Marital status was controlled for in the analyses of ever-use of a modern method and transition to live birth. Because of the high correlation between marital status and sexual experience in these samples, the former variable was not used in predicting transition to first sex. All regressions were conducted using Stata version 10SE and adjusted for sample weights.

\section{RESULTS}

\section{Demographic Characteristics}

The majority of 15-19-year-old females in El Salvador and Nicaragua lived in urban areas at all four time points; in Honduras, the percentage residing in urban areas in- creased over the study period, becoming a majority only in 2005-2006 (Table 2). In Guatemala, a majority of adolescents lived in rural areas during all surveys. Adolescents' education levels improved in all four countries: The percentage with no education declined across the survey years, and the percentage with a secondary or higher education steadily increased over the period. Socioeconomic status also improved, as the percentage of women in the low socioeconomic category decreased between the first and fourth surveys for each country. The 15-19 age-group represented about a quarter of the total population of women in the samples for all surveys in all countries (range, 22-27\%; not shown).

\section{Trends in Reproductive Health Behavior}

- Ever had sexual intercourse. The proportion of 15-19year-olds in El Salvador who had ever had sex remained stable between 1988 and 2002-2003 (31-33\%; Figure 1). In Guatemala, the proportion who had ever had sex declined between 1987 and 2002 (from 29\% to 24\%). The proportions reporting sexual intercourse in Honduras and Nicaragua were the same for the first and fourth surveys; however, in Nicaragua, this percentage declined in the interim years (from 40\% in 1992-1993 to a low of 35\% in 2001), while in Honduras, it rose (from 31\% in 19911992 to a high of $38 \%$ in 2001).

- Ever been in a union. In all four countries, the proportion of adolescents who had ever been in a legal or consensual union declined over time. El Salvador saw a decline from $29 \%$ in 1988 to 22\% in 2002-2003. In Guatemala and Honduras, $26 \%$ had been in a union at the first survey (1987 and 1991-1992, respectively); at the final surveys 


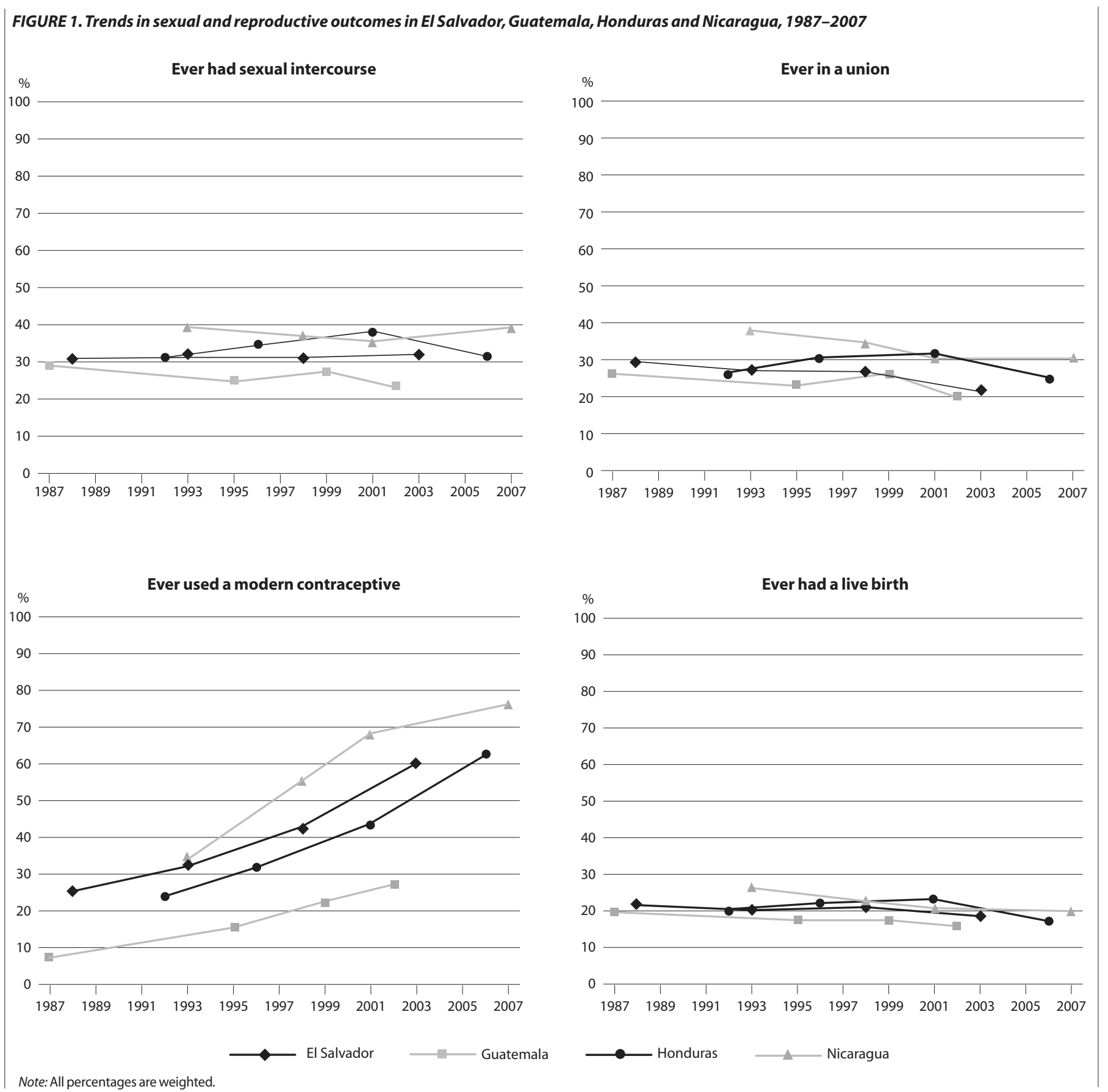

(2002 and 2005-2006, respectively), the proportion had declined to 20\% for Guatemala, but had changed little for Honduras (25\%). Nicaragua had the highest proportion of adolescent unions in the first and last survey years (37\% and 30\%, respectively).

- Ever used a modern contraceptive. The proportion of sexually experienced adolescents who reported ever having used a modern contraceptive method rose sharply in all four countries over the study period. Adolescents in El Salvador and Honduras reported similar rates at the first surveys ( $25 \%$ and $24 \%$, respectively); by the fourth surveys, these percentages had increased to $60 \%$ and $62 \%$, respectively. Guatemalan adolescents had the lowest initial rate of modern contraceptive use-7\% in 1987-which almost quadrupled over subsequent surveys, to $27 \%$ in 2002 . In Nicaragua, the percentage who reported ever having used a modern contraceptive increased from 35\% in 19921993 to 76\% in 2006-2007.

- Ever had a live birth. Although the percentage of adolescents who had ever had a live birth declined in all four countries over time, the declines were modest in El Salvador, Guatemala and Honduras (three percentage points in each country). By contrast, the percentage of adolescents who had had a live birth in Nicaragua, which was higher than in the other three countries at the first survey, dropped from $26 \%$ to $20 \%$ by the fourth survey. 
TABLE 3. Hazard and odds ratios from regression analyses to identify associations between sexual and reproductive health outcomes and selected variables, El Salvador, 1988-2003

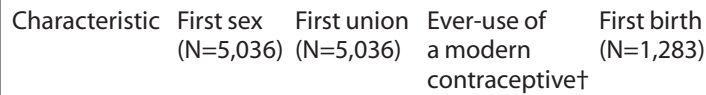

\begin{tabular}{|c|c|c|c|c|}
\hline \multicolumn{5}{|l|}{ Survey year } \\
\hline 1988 (ref) & 1.00 & 1.00 & 1.00 & 1.00 \\
\hline 1993 & $0.49^{* *}$ & $0.39 * *$ & $2.30^{*}$ & 0.64 \\
\hline 1998 & $1.75^{* *}$ & $1.51^{*}$ & $3.27^{* *}$ & 1.33 \\
\hline 2002-2003 & $2.12^{* *}$ & $1.50^{*}$ & $7.03^{* *}$ & 1.18 \\
\hline Age $\neq$ & 1.02 & 1.06 & 1.19 & $0.63^{* *}$ \\
\hline \multicolumn{5}{|l|}{ Residence } \\
\hline Rural (ref) & 1.00 & 1.00 & 1.00 & 1.00 \\
\hline Urban & $1.25^{*}$ & 1.12 & 1.25 & 0.80 \\
\hline \multicolumn{5}{|c|}{ Education level } \\
\hline None (ref) & 1.00 & 1.00 & 1.00 & 1.00 \\
\hline Primary & 0.79 & 0.82 & 1.47 & 1.36 \\
\hline Secondary & $0.31^{* *}$ & $0.26^{* *}$ & 1.87 & 1.11 \\
\hline \multicolumn{5}{|c|}{ Socioeconomic status } \\
\hline Low (ref) & 1.00 & 1.00 & 1.00 & 1.00 \\
\hline Medium & 1.05 & 1.01 & $2.24^{*}$ & 0.82 \\
\hline High & $0.67^{*}$ & $0.51^{* *}$ & $1.93^{* *}$ & 0.79 \\
\hline Ever in union & u & u & 1.53 & $2.03^{*}$ \\
\hline
\end{tabular}

${ }^{*} \mathrm{p} \leq .05$. ${ }^{* *} \mathrm{p} \leq .01$. Includes the pill, condom, IUD, injection, implant, and male or female sterilization. $¥$ Age at first sex was used in the first birth analysis. Notes: Sample sizes are smaller than in Table 1 because of missing data for some of the variables included in the model. ref=reference category. $u=$ unavailable.

\section{Multivariate Analyses}

To supplement the examination of the basic trends in sexual and reproductive health outcomes among adolescent females in Central America, multivariate analyses tested for significant changes in these behaviors over time.

- El Salvador. After controlling for age, residence, education level and socioeconomic status, the risk of adolescents having had sexual intercourse, compared with their risk in 1988, declined in 1993 (hazard ratio, 0.5), but rose in the last two survey years (1.8 and 2.1, respectively; Table 3). Similarly, the likelihood of an adolescent entering her first union was lower in 1993 (0.4), but higher in the later surveys ( 1.5 for each). Adolescents had higher odds of having ever used a modern contraceptive in the three later surveys than in the base year (odds ratios, 2.3, 3.3 and 7.0, respectively). Notably, the odds of giving birth for the first time did not change significantly for adolescents in El Salvador over the study period.

When the survey year was controlled for, adolescents in urban areas were more likely to have ever had sex than adolescents in rural areas (hazard ratio, 1.3). However, adolescents with at least a secondary education and those in the high socioeconomic bracket had lower odds than those with no education and those in the low socioeconomic bracket of having had sex (0.3 and 0.7 , respectively) and of entering their first union ( 0.3 and 0.5 , respectively). Among sexually active adolescents, those in the medium and high socioeconomic categories were more likely than those in the low category to have ever used a modern contraceptive (odds ratios, 2.2 and 1.9, respectively). Finally, adolescents who were older at first sex had reduced odds of having given birth (0.6), while those who had ever been in a legal or consensual union had elevated odds (2.0).

- Guatemala. The odds that Guatemalan adolescents had ever used a modern contraceptive method increased significantly at each survey after the 1987 base survey, rising from 1.9 in 1995 to 4.1 and 4.9 in 1998-1999 and 2002, respectively (Table 4). No significant changes in the odds of first sex, first union or first birth among adolescents were found over the survey years.

In Guatemala, older adolescents had increased odds of having had their first sex, entered their first union or ever used a modern contraceptive method (hazard ratios, 1.3 and 1.3, and odds ratio, 1.2, respectively); however, adolescents' risk of having given birth was negatively associated with their age at first sex (0.6). Compared with adolescents with no education or low socioeconomic status, those with primary or secondary education (0.7 and 0.2, respectively), and those in the medium or high socioeconomic categories (0.8-0.9 and 0.6, respectively), had reduced odds of having had sex and of entering their first union. By contrast, sexually active adolescents with primary or secondary education were more likely than those with no education to have used a modern method (2.3 and 4.0, respectively), while adolescents with medium or high socioeconomic status were more likely than those

\section{TABLE 4. Hazard and odds ratios from regression analyses to identify associations between sexual and reproductive health outcomes and selected variables, Guatemala,} 1987-2002

Characteristic First sex First union Ever-use of First birth $(\mathrm{N}=7,116) \quad(\mathrm{N}=7,116) \quad$ a modern $\quad(\mathrm{N}=2,160)$ contraceptivet $(\mathrm{N}=2,160)$

\begin{tabular}{|c|c|c|c|c|}
\hline \multicolumn{5}{|l|}{ Survey year } \\
\hline 1987 (ref) & 1.00 & 1.00 & 1.00 & 1.00 \\
\hline 1995 & 0.94 & 0.97 & $1.93^{*}$ & 1.15 \\
\hline 1998-1999 & 1.03 & 1.08 & $4.07^{* *}$ & 1.19 \\
\hline 2002 & 0.97 & 0.93 & $4.85^{* *}$ & 1.15 \\
\hline Age $\neq$ & $1.31^{* *}$ & $1.28^{* *}$ & $1.23^{*}$ & $0.56^{* *}$ \\
\hline \multicolumn{5}{|l|}{ Residence } \\
\hline Rural (ref) & 1.00 & 1.00 & 1.00 & 1.00 \\
\hline Urban & 0.99 & 1.00 & 1.34 & 0.95 \\
\hline \multicolumn{5}{|c|}{ Education level } \\
\hline None (ref) & 1.00 & 1.00 & 1.00 & 1.00 \\
\hline Primary & $0.68^{* *}$ & $0.66^{* *}$ & $2.30^{* *}$ & 1.20 \\
\hline Secondary & $0.20^{* *}$ & $0.16^{* *}$ & $3.96^{* *}$ & 1.16 \\
\hline \multicolumn{5}{|c|}{ Socioeconomic status } \\
\hline Low (ref) & 1.00 & 1.00 & 1.00 & 1.00 \\
\hline Medium & $0.86^{*}$ & $0.83^{*}$ & $3.43^{* *}$ & 0.90 \\
\hline High & $0.63^{*}$ & $0.55^{*}$ & $9.51^{* *}$ & 0.76 \\
\hline Ever in union & $\mathrm{u}$ & $\mathrm{u}$ & $3.42^{*}$ & 1.12 \\
\hline
\end{tabular}

${ }^{*} \mathrm{p} \leq .05 .{ }^{* *} \mathrm{p} \leq .01$. Includes the pill, condom, IUD, injection, implant, and male or female sterilization. $¥$ Age at first sex was used in the first birth analysis. Notes: Sample sizes are smaller than in Table 1 because of missing data for some of the variables included in the model. ref=reference category. $\mathrm{u}=$ unavailable. 
with low status to have used such a method (3.4 and 9.5, respectively). As expected, adolescents who had ever been in a union had higher odds than those who had not of having ever used a modern contraceptive (3.4).

- Honduras. Adolescents in each of the three later surveys were more likely than those in the base survey to have experienced sexual intercourse (hazard ratios, 4.5-5.7; Table 5), while adolescents in the third and fourth surveys also had elevated odds of having ever used a modern contraceptive (odds ratios, 2.5 and 5.9, respectively).

Older adolescents and those living in urban areas were more likely than their younger and rural counterparts to have had sex (hazard ratios, 1.1 and 1.2, respectively). Adolescents with primary or secondary education, and those with high socioeconomic status, however, had lower odds of experiencing first sex than did adolescents with no education or low socioeconomic status (0.3-0.7). Similarly, older adolescents had higher odds of forming a union than did younger adolescents (1.2), while adolescents with any education and those with high socioeconomic status had lower odds of entering their first union than did their counterparts (0.3-0.8). The likelihood of having ever used a modern method was higher among older adolescents, adolescents in urban areas, those with any education, those with medium or high socioeconomic status, and those who had ever been in a union than among other respondents (odds ratios, 1.2-3.0). Adolescents who were older at first sex had reduced odds of hav-

\begin{tabular}{|c|c|c|c|c|}
\hline Characteristic & $\begin{array}{l}\text { First sex } \\
(\mathrm{N}=8,858)\end{array}$ & $\begin{array}{l}\text { First union } \dagger \\
(\mathrm{N}=8,858)\end{array}$ & $\begin{array}{l}\text { Ever-use of } \\
\text { a modern } \\
\text { contraceptive } \neq \\
(\mathrm{N}=2,784)\end{array}$ & $\begin{array}{l}\text { First birth } \\
(\mathrm{N}=2,784) \\
\end{array}$ \\
\hline \multicolumn{5}{|c|}{ Survey year } \\
\hline $1991-1992$ (ref) & 1.00 & u & 1.00 & 1.00 \\
\hline 1996 & $4.52^{* *}$ & 1.00 & 1.61 & $0.60^{*}$ \\
\hline 2001 & $5.72^{* *}$ & $1.21 *$ & $2.45^{*}$ & 0.67 \\
\hline 2005-2006 & $5.21^{* *}$ & 1.00 & $5.92^{* *}$ & 0.70 \\
\hline Age§ & $1.08^{* *}$ & $1.19^{* *}$ & $1.20^{* *}$ & $0.71^{* *}$ \\
\hline \multicolumn{5}{|l|}{ Residence } \\
\hline Rural (ref) & 1.00 & 1.00 & 1.00 & 1.00 \\
\hline Urban & $1.18^{*}$ & 1.09 & $1.34^{*}$ & 0.86 \\
\hline \multicolumn{5}{|l|}{ Education level } \\
\hline None (ref) & 1.00 & 1.00 & 1.00 & 1.00 \\
\hline Primary & $0.72^{*}$ & $0.77^{*}$ & $1.59^{*}$ & 0.98 \\
\hline Secondary & $0.28^{* *}$ & $0.27^{* *}$ & $1.91 *$ & 0.79 \\
\hline \multicolumn{5}{|c|}{ Socioeconomic status } \\
\hline Low (ref) & 1.00 & 1.00 & 1.00 & 1.00 \\
\hline Medium & 1.01 & 0.95 & $2.42^{* *}$ & 0.97 \\
\hline High & $0.54^{* *}$ & $0.42^{* *}$ & $2.10^{* *}$ & 0.72 \\
\hline Ever in union & u & $\mathrm{u}$ & $3.03^{* *}$ & $2.16^{* *}$ \\
\hline \multicolumn{5}{|c|}{$\begin{array}{l}{ }^{*} \mathrm{p} \leq .05 .{ }^{* *} \mathrm{p} \leq .01 . \text { +Because first union data were not collected in the } \\
1991-1992 \text { survey, the } 1996 \text { survey is the reference category. } \text { Includes the } \\
\text { pill, condom, IUD, injection, implant, and male or female sterilization. \$Age at } \\
\text { first sex was used in the first birth analysis. Notes: Sample sizes are smaller } \\
\text { than in Table } 1 \text { because of missing data for some of the variables included in } \\
\text { the model. ref=reference category. } u=\text { unavailable. }\end{array}$} \\
\hline
\end{tabular}

TABLE 6. Hazard and odds ratios from regression analyses to identify associations between sexual and reproductive health outcomes and selected variables, Nicaragua, 1992-2007

Characteristic First sex First union Ever-use of First birth $(\mathrm{N}=9,620) \quad(\mathrm{N}=9,620)$ a modern $\quad(\mathrm{N}=3,844)$ contraceptive $†$ $(\mathrm{N}=3,844)$

\begin{tabular}{|c|c|c|c|c|}
\hline \multicolumn{5}{|l|}{ Survey year } \\
\hline \multicolumn{2}{|c|}{ 1992-1993 (ref) 1.00} & \multirow{2}{*}{$\begin{array}{l}1.00 \\
0.59^{* *}\end{array}$} & \multirow{2}{*}{$\begin{array}{l}1.00 \\
1.92^{* *}\end{array}$} & \multirow{2}{*}{$\begin{array}{l}1.00 \\
0.95\end{array}$} \\
\hline 1998 & 1.04 & & & \\
\hline 2001 & 1.00 & $0.50^{* *}$ & $3.62^{* *}$ & $0.80^{*}$ \\
\hline 2006-2007 & $1.24^{*}$ & $0.52^{* *}$ & $7.04^{* *}$ & $0.65^{* *}$ \\
\hline Age‡ & $1.14^{* *}$ & 1.01 & $1.21 * *$ & $0.60 * *$ \\
\hline \multicolumn{5}{|l|}{ Residence } \\
\hline Rural (ref) & 1.00 & 1.00 & 1.00 & 1.00 \\
\hline Urban & $1.19^{*}$ & $1.11^{*}$ & $1.33^{*}$ & 1.14 \\
\hline \multicolumn{5}{|c|}{ Education level } \\
\hline None (ref) & 1.00 & 1.00 & 1.00 & 1.00 \\
\hline Primary & $0.79 *$ & $0.74^{* *}$ & $1.46^{*}$ & 0.87 \\
\hline Secondary & $0.34^{* *}$ & $0.32^{* *}$ & $1.36^{*}$ & $0.73^{*}$ \\
\hline \multicolumn{5}{|c|}{ Socioeconomic status } \\
\hline Low (ref) & 1.00 & 1.00 & 1.00 & 1.00 \\
\hline Medium & $0.80^{* *}$ & $0.82^{* *}$ & 1.22 & $0.84^{*}$ \\
\hline High & $0.63^{* *}$ & $0.62^{*}$ & $1.57^{*}$ & $0.77^{*}$ \\
\hline Ever in union & $\mathrm{u}$ & $\mathrm{u}$ & $4.46^{* *}$ & $1.85^{* *}$ \\
\hline
\end{tabular}

${ }^{*} \mathrm{p} \leq .05 .{ }^{* *} \mathrm{p} \leq .01$. Includes the pill, condom, IUD, injection, implant, and male or female sterilization. ¥Age at first sex was used in the first birth analysis. Notes: Sample sizes are smaller than in Table 1 because of missing data for some of the variables included in the model. ref=reference category. $\mathrm{u}=$ unavailable.

ing had a live birth (0.7), while those who had entered a union had elevated odds (2.2).

- Nicaragua. Compared with Nicaraguan adolescents surveyed in 1992-1993, those surveyed in 2006-2007 were more likely to have had sexual intercourse (hazard ratio, 1.2), and those in the three most recent surveys were more likely to have ever used a modern contraceptive method (odds ratios, 1.9-7.0; Table 6). By contrast, adolescents in the three most recent surveys had reduced odds of having entered a first union (0.5-0.6), and those in the last two surveys had reduced odds of having given birth (0.7-0.8).

Urban adolescents had higher odds than their rural counterparts of having experienced first sex and first union (hazard ratios, 1.2 and 1.1, respectively), whereas adolescents with any education or with medium or high socioeconomic status had lower odds of having had first sex (0.3-0.8) or having entered a union (0.3-0.8) than those with no schooling or low socioeconomic status. In addition, older adolescents had higher odds than their younger counterparts of ever having had sex (1.1). Furthermore, in Nicaragua, being older, living in an urban area, having any education and having high socioeconomic status were associated with ever-use of a modern contraceptive (odds ratios, 1.2-1.6). Adolescents who had ever been in a union were significantly more likely than those who had not to have used a modern method (4.5). Factors associated with a lower risk of having given birth were older age at first sex, having a secondary edu- 
cation, and having medium or high socioeconomic status (0.6-0.8); only having been in a union is associated with higher odds (1.9).

\section{DISCUSSION}

This study improves our understanding of the trends in sexual and reproductive behaviors among adolescent females in El Salvador, Guatemala, Honduras and Nicaragua over the past two decades. Many behaviors have changed significantly in these countries, and this comparative analysis shows that after individual characteristics have been accounted for, adolescent sexual activity has increased in El Salvador, Honduras and Nicaragua, but remained static in Guatemala. The likelihood of being in a union has decreased among Nicaraguan adolescents, whereas in El Salvador it has increased; union status has remained largely unchanged in both Honduras and Guatemala. By contrast, ever-use of modern contraceptives has significantly increased among adolescents in all four countries over time.

Despite the general increase in modern contraceptive use, however, only Nicaragua experienced a significant decline in first births among adolescents over the 15-year period. In El Salvador and Honduras, increased use coincided with substantial increases in the likelihood of reporting first sexual intercourse, while in Guatemala, a steep rise in use was not matched by an increase in sexual debut or in a decline in first births. There are several possible explanations for these seemingly incongruent findings. Since the measure for use of a modern contraceptive was restricted to ever-use rather than current use, the rise in method use may mask continued unmet need or inconsistent use of contraceptives. Furthermore, contraceptive failure-which is known to be high among adolescentsmay explain why higher rates of use have not translated into delayed first births. ${ }^{38}$ Finally, increased contraceptive use may be attributed to adolescents' efforts to space a second birth. A similar study has confirmed that rates of unwanted or mistimed first births are high among adolescents in Central America, and that rates of contraceptive use are higher among adolescents with one child than among those with none. ${ }^{39}$

Urban residence, education and socioeconomic status were important predictors of adolescent sexual and reproductive outcomes. Adolescent females with no education were more likely than those with primary or secondary schooling to have had sex and to have entered a union at early ages, and were less likely to have used a modern contraceptive. However, education had little relation to the likelihood of having a first live birth, with the exception of secondary education in Nicaragua, which was associated with a slightly reduced risk. Urban residence was an unreliable predictor of adolescent behavior, being associated with increased odds of first sex, first union and contraceptive use in only a few cases, and having no association with first birth. At the bivariate level, urban residence is often associated with a reduced likelihood of transition to first sex, first union and childbearing; however, when education and socioeconomic status are controlled for, this relationship can reverse or become mixed. ${ }^{40}$

Although education and urban residence often serve as proxies for socioeconomic status, this study shows that a unique proxy measure of socioeconomic status accounts for additional differences in behavior. Adolescent females with low socioeconomic status were more likely to have had sex or to have ever been in a union, and were less likely to have used a modern contraceptive, than were adolescents in higher socioeconomic brackets. In Nicaragua, adolescents with low socioeconomic status were also more likely to have had a live birth than were those with either medium or high status. These findings are consistent with prior research that demonstrated the importance of adolescents' educational attainment, socioeconomic status and older age in union formation, sexual activity and childbearing. ${ }^{5,41-45}$

In other studies that have explored adolescent sexual and reproductive behavior in Latin America, declines in fertility and increases in use of modern contraceptives occurred among women aged 15-19. ${ }^{46,47}$ In addition, studies of adolescents in this region have examined other contextual factors, such as family influences, community- or national-level economic factors, and individual characteristics such as pregnancy intendedness and exposure to family planning messages and to sex education. ${ }^{39,47-49}$ However, none of these studies provided a statistical basis for understanding the importance of sexual and reproductive health changes over time. Furthermore, unlike this study, they did not examine associations between adolescent outcomes and individual characteristics while controlling for changes across time.

\section{Limitations}

This study has several limitations. First, because of the range of survey dates and sources, the questions that elicited the data for the variables used in this analysis, while similar, were not always identical. Second, the data were based on multiple cross-sectional surveys, which bars assertions of causality between the outcomes of interest and the associated social and demographic characteristics. Finally, because this study focused on adolescents aged 15-19, it may misrepresent ongoing changes in the four target countries by omitting adolescents who had not yet had an opportunity to experience the various outcomes (e.g., sexual debut, marriage and first birth). One way to control for this censoring would be to include only women aged 20-24 or 25-29. This approach was not taken, because the primary interest was in adolescent behaviors as they occur in each time period.

\section{Conclusions}

This study serves as a starting point for exploring trends in adolescent sexual and reproductive behaviors in Central America. Future research could build on this work to further explain trends in adolescent outcomes and to identify additional factors associated with these behaviors. Some important factors to incorporate into future analyses in- 
clude adolescents' exposure to mass media campaigns or sex education, pregnancy intendedness and adolescent childbearing, as well as broader contextual factors (such as family and community influences) that have been identified as important factors in the sexual behavior of Latin American adolescents. ${ }^{48}$ The timing of first sex, first union and first birth for adolescents should also be defined more precisely to identify the specific ages at which these events occur, and to explore the sequential relationship between sexual experience, unions and births (e.g., what proportion of sexual activity occurs prior to marital unions, and whether unions tend to precede or follow live births). An assessment of national- and community-level interventions would also increase our understanding of what programs and policies may have contributed to the positive changes in adolescent sexual behaviors in Central American countries, and what further efforts should be undertaken.

The associations between age, education, socioeconomic status, and adolescent sexual and reproductive outcomes revealed in this study suggest that continued programmatic and policy initiatives should be directed at improving adolescents' overall situation as a means of improving their sexual health. Indeed, interventions that increase basic education, provide comprehensive sex education and support the economic development of youth have been shown to improve sexual and reproductive outcomes for adolescents in developing countries by delaying the onset of sexual activity or union formation and increasing the use of family planning services. ${ }^{50-54}$ By focusing increased efforts on the reproductive health needs of adolescents in El Salvador, Guatemala, Honduras and Nicaragua, it may be possible to alter future trends and help improve the health and well-being for adolescents across Central America.

\section{REFERENCES}

1. United Nations Population Fund (UNFPA), State of the World Population: Adolescents and Young People, New York: UNFPA, 2004.

2. Buvinic M, The costs of adolescent childbearing: evidence from Chile, Barbados, Guatemala, and Mexico, Studies in Family Planning, 1998, 29(2):201-209.

3. Madhavan S and Thomas K, Early childbearing and schooling: new evidence from South Africa, Comparative Education Review, 2005 , 49(4):452-467.

4. Olausson PO et al., Teenage childbearing and long-term socioeconomic consequences: a case study in Sweden, Family Planning Perspectives, 2001, 33(2):70-74.

5. Rani M and Lule E, Exploring the socioeconomic dimension of adolescent reproductive health: a multicountry analysis, International Family Planning Perspectives, 2004, 30(3):110-117.

6. Gasparini L, Gutierrez F and Tornarolli L, Growth and income poverty in Latin America and the Caribbean: evidence from household surveys, Review of Income and Wealth, 2007, 53(2):209-245.

7. World Development Indicators database, Gross national income per capita 2008, World Bank, Oct. 7, 2009, <http:// siteresources.worldbank.org/DATASTATISTICS/Resources/GNIPC.pdf>, accessed Feb. 3, 2009.

8. Conde-Agudelo A, Belizán JM and Lammers C, Maternal-perinatal morbidity and mortality associated with adolescent pregnancy in Latin America: cross-sectional study, American Journal of Obstetrics $\varepsilon$ Gynecology, 2005, 192(2):342-349.
9. Kumar A et al., Outcome of teenage pregnancy, Indian Journal of Pediatrics, 2007, 74(10):927-931.

10. Mahavarkar SH, Madhu CK and Mule VD, A comparative study of teenage pregnancy, Journal of Obstetrics and Gynecology, 2008, 28(6): 604-607.

11. Usta IM et al., Obstetric outcome of teenage pregnancies compared with adult pregnancies, Acta Obstetricia et Gynecologica Scandinavica, 2008, 87(2):178-183.

12. Olukoya AA et al., Unsafe abortion in adolescents, International Journal of Gynecology \& Obstetrics, 2001, 75(2):137-147.

13. World Health Organization (WHO), Unsafe Abortion: Global and Regional Estimates of Incidence of Unsafe Abortion and Associated Mortality in 2000, Geneva: WHO, 2004.

14. WHO, Why is giving special attention to adolescents important for achieving Millennium Development Goal 5? Fact sheet WHO/MPS/08.14, 2008, <http://www.who.int/making_pregnancy_ safer/events/2008/mdg5/adolescent_preg.pdf>, accessed Feb. 16, 2010.

15. Botting B, Rosato M and Wood R, Teenage mothers and the health of their children, Population Trends, 1998, 93(autumn):19-28.

16. Chen XK et al., Teenage pregnancy and adverse birth outcomes: a large population based retrospective cohort study, International Journal of Epidemiology, 2007, 36(2):368-373.

17. Fraser AM, Brockert JE and Ward RH, Association of young maternal age with adverse reproductive outcomes, New England Journal of Medicine, 1995, 332(17):1113-1117.

18. Gilbert W et al., Birth outcomes in teenage pregnancies, Journal of Maternal-Fetal and Neonatal Medicine, 2004, 16(5):265-270.

19. Gortzak-Uzan L et al., Teenage pregnancy: risk factors for adverse perinatal outcome, Journal of Maternal-Fetal and Neonatal Medicine, 2001, 10(6):393-397.

20. Olausson PO, Cnattingius S and Haglund B, Teenage pregnancies and risk of late fetal death and infant mortality, British Journal of Obstetrics and Gynaecology, 1999, 106(2):116-121.

21. Zabin LS and Kiragu K, The health consequences of adolescent sexual and fertility behavior in Sub-Saharan Africa, Studies in Family Planning, 1998, 29(2):210-232.

22. Buchholz ES and Korn-Bursztyn C, Children of adolescent mothers: are they at risk for abuse? Adolescence, 1993, 28(110):361-382.

23. Wakschlag L and Hans S, Early parenthood in context: implications for development and intervention, in: Zeanah C, ed., Handbook of Infant Mental Health, New York: Guilford Press, 2000.

24. Corcoran J, Consequences of adolescent pregnancy/parenting: a review of the literature, Social Work in Health Care, 1998, 27(2):49-67.

25. Fergusson DM and Woodward LJ, Maternal age and educational and psychosocial outcomes in early adulthood, Journal of Child Psychology and Psychiatry, 1999, 40(3):479-489.

26. Jaffee $S$ et al., Why are children born to teen mothers at risk for adverse outcomes in young adulthood? Results from a 20-year longitudinal study, Development and Psychopathology, 2001, 13(2):377-397.

27. Asociación Demográfica Salvadoreña (ADS), Encuesta Nacional de Salud Familiar, 2002/2003, San Salvador, El Salvador: ADS; and Atlanta, GA, USA: Centers for Disease Control and Prevention (CDC), 2004.

28. Instituto Nacional de Estadísticas y Censos (INEC) and Ministerio de Salud, Encuesta Nicaragüense de Demografía y Salud, 2006-2007, Managua, Nicaragua: INEC and Ministerio de Salud; and Atlanta, GA USA: CDC, 2007.

29. Ministerio de Salud Pública y Asistencia Social (MSPAS), Encuesta Nacional de Salud Materno Infantil, 2002, Guatemala City, Guatemala: MSPAS; and Atlanta, GA, USA: CDC, 2003.

30. Secretaría de Salud, Instituto Nacional de Estadística (INE) and Macro International, Encuesta Nacional de Demografía y Salud, 20052006, Tegucigalpa, Honduras: Secretaría de Salud and INE; and Calverton, MD, USA: Macro International, 2006. 
31. WHO, Statistical Information System database, 2009, <http://who. int/whosis/en/>, accessed Feb. 12, 2009

32. Machinea J, Bárcena A and León A, The Millennium Development Goals: A Latin American and Caribbean Perspective, Santiago, Chile: Economic Commission for Latin America and the Caribbean, 2005.

33. UN Economic Commission for Latin America and the Caribbean, Infant mortality rate, by sex, by five-year periods, $2010,<$ http://websie. eclac.cl/anuario estadistico/anuario_2009/datos/1.4.2.xls>, accessed Feb. 16, 2009.

34. Pena R, Wall S and Persson LA, The effect of poverty, social inequity, and maternal education on infant mortality in Nicaragua, 1988-1993, American Journal of Public Health, 2000, 90(1):64-69

35. Szwarcwald CL, Andrade CL and Bastos FI, Income inequality, residential poverty clustering and infant mortality: a study in Rio de Janeiro, Brazil, Social Science \& Medicine, 2002, 55(12):2083-2092.

36. Filmer D and Pritchett L, Estimating wealth effects without expenditure data-or tears: an application to educational enrollments in states of India, Demography, 2001, 38(1):115-132.

37. Vyas S and Kumaranayake L, Constructing socioeconomic status indices: how to use principal components analysis, Health Policy and Planning, 2006, 21(6):459-468.

38. Blanc A et al., Patterns and trends in adolescents' contraceptive use and discontinuation in developing countries and comparisons with adult women, International Perspectives on Sexual and Reproductive Health, 2009, 35(2):63-71

39. Remez L et al., Ensuring a Healthier Tomorrow in Central America: Protecting the Sexual and Reproductive Health of Today's Youth, New York: Guttmacher Institute, 2008.

40. Chackiel J and Schkolnik S, Latin America: overview of the fertility transition, 1950-1990, in: Guzman J et al., eds., The Fertility Transition in Latin America, Oxford, England: Oxford University Press, 1996, pp. 3-26.

41. Gigante DP et al., Risk factors for childbearing during adolescence in a population-based birth cohort in southern Brazil, Revista Panamericana de Salud Pública, 2004, 16(1):1-10.

42. Gupta N and Mahy M, Adolescent childbearing in Sub-Saharan Africa: can increased schooling alone raise ages at first birth? Demographic Research, 2003, Vol. 8, Art. 4, pp. 93-106, <http://www. demographic-research.org/Volumes/Vol8/4/default.htm>, accessed Feb. 12, 2009

43. Heaton T, Forste R and Otterstrom S, Family transitions in Latin America: first intercourse, first union and first birth, International Journal of Population Geography, 2002, 8(1):1-15.

44. Martin TC, Women's education and fertility: results from 26 Demographic and Health Surveys, Studies in Family Planning, 1995 26(4): 187-202.

45. Singh S, Darroch JE and Frost JJ, Socioeconomic disadvantage and adolescent women's sexual and reproductive behavior: the case of five developed countries, Family Planning Perspectives, 2001, 33(6):251289

46. Ali MM and Cleland J, Sexual and reproductive behaviour among single women aged 15-24 in eight Latin American countries: a comparative analysis, Social Science $\&$ Medicine, 2005, 60(6):1175-1185.

47. Schutt-Aine J and Maddaleno M, Sexual Health and Development of Adolescents and Youth in the Americas: Program and Policy Implications, Washington, DC: Pan-American Health Organization, 2003.

48. Flórez CE and Núñez J, Teenage Childbearing in Latin American Countries, Washington, DC: Inter-American Development Bank, 2001.

49. Monteith R, Stupp P and McCracken S, Reproductive, Maternal, and Child Health in Central America: Trends and Challenges Facing Women and Children, Atlanta, GA, USA: CDC and U.S. Agency for International Development, 2005

50. Bearinger LH et al., Global perspectives on the sexual and reproductive health of adolescents: patterns, prevention, and potential, Lancet, 2007, 369(9568):1220-1231.

51. Levitt-Dayal M, Adolescent girls in India choose a better future: an impact assessment, in: Botts S, ed., Adolescent Sexual and Reproductive Health: Evidence and Program Implications for South Africa, Geneva: WHO, 2002.

52. Raffaelli M et al., Sexual practices and attitudes of street youth in Belo Horizonte, Brazil, street youth study group, Social Science $E$ Medicine, 1993, 37(5):661-670.

53. Toledo $\mathrm{V}$ et al., Impact of the sexual education program: adoles cence, time for decisions, Revista de la Sociedad Chilena de Obstetricia y Ginecología Infantil y de la Adolescencia, 2000, 7(3):73-86 (in Spanish)

54. Wilder J, Masilamani R and Mathew A, Reproductive Health of Young Adults in India: The Road to Public Health, Watertown, MA, USA: Pathfinder International, 2006.

\section{RESUMEN}

Contexto: Comparada con el promedio latinoamericano, la fecundidad en adolescentes es alta en El Salvador, Guatemala, Honduras y Nicaragua; estos países también tienen altos niveles de pobreza y un acceso limitado a servicios de salud reproductiva.

Métodos: Para cada país, los datos fueron extraídos de cuatro encuestas nacionales de salud, realizadas entre 1987 y 2007; y el análisis se enfocó en las tendencias del comportamiento sexual y reproductivo en mujeres adolescentes de 15-19 años de edad. A través del análisis de eventos que ocurrieron en el pasado, se examinaron las transiciones a la primera relación sexual, la primera unión y el primer nacimiento vivo a lo largo de los años de las encuestas; aplicando análisis de regresión de riesgos de Cox y regresión logística se evaluaron las asociaciones entre características demográficas selectas y estos resultados, así como también el haber usado alguna vez un método anticonceptivo moderno.

Resultados: La probabilidad de que las mujeres adolescentes hayan empezado a tener relaciones sexuales ha aumentado a través del tiempo en El Salvador, Honduras y Nicaragua; y ha permanecido estable en Guatemala. Mientras tanto, las probabilidades de haber establecido su primera unión han disminuido en Nicaragua y aumentado en El Salvador, pero no han cambiado en Honduras y Guatemala. Notablemente, la probabilidad de que las adolescentes hayan usado alguna vez un método anticonceptivo ha aumentado en los cuatro países en los años de las encuestas. Durante el período de estudio, la probabilidad de que las adolescentes nicaragüenses hayan tenido su primer nacimiento vivo disminuyó significativamente. Finalmente, la residencia urbana, el nivel de educación y la condición socioeconómica fueron vaticinadores importantes de los resultados sexuales y reproductivos de las adolescentes.

Conclusiones: Las iniciativas de programas y políticas deben enfocarse en el mejoramiento de la educación de las adolescentes y sus perspectivas socioeconómicas; y; en particular, se necesitan realizar esfuerzos para ayudar a las adolescentes a que retrasen la edad en la cual se vuelven sexualmente activas y establecen su primera unión.

\section{RÉSUMÉ}

Contexte: Par rapport à la moyenne d'Amérique latine, la fécondité adolescente est élevée au Salvador, au Guatemala, au Honduras et au Nicaragua-quatre pays présentant aussi de hauts niveaux de pauvreté et un faible accès aux soins de santé 
génésique.

Méthodes: Pour chaque pays, les données sont tirées de quatre enquêtes de santé nationales menées entre 1987 et 2007 et l'analyse se concentre sur les tendances de comportement sexuel et génésique des adolescentes de 15 à 19 ans. Les transitions vers les premiers rapports sexuels, la première union et la première naissance vivante sur la période des années d'enquête sont examinées par analyse historique d'événements. Les associations entre certaines caractéristiques démographiques et ces événements, de même que le fait d'avoir jamais pratiqué une méthode contraceptive moderne, sont évaluées par analyses de régression à effet proportionnel de Cox et analyses de régression logistique.

Résultats: La probabilité d'activité sexuelle des adolescentes a augmenté avec le temps au Salvador, au Honduras et au Nicaragua mais est restée stable au Guatemala. Dans le même temps, la probabilité d'engagement dans une première union a diminué au Nicaragua et augmenté au Salvador, sans changer au Honduras ni au Guatemala. La probabilité pour les adolescentes d'avoir jamais pratiqué une méthode contracep- tive moderne a augmenté dans les quatre pays sur la période des enquêtes. Les adolescentes du Nicaragua sont devenues significativement moins susceptibles de connaître leur première naissance vivante durant la période de l'étude. Enfin, la résidence en milieu urbain, le niveau d'éducation et le rang socioéconomique se sont avérés d'importants prédicteurs quant aux aboutissements sexuels et génésiques des adolescentes.

Conclusions: Les initiatives programmatiques et politiques doivent se concentrer sur l'amélioration des perspectives d'éducation et socioéconomiques des adolescentes. Il est surtout nécessaire d'aider les adolescentes à différer l'âge auquel elles deviennent sexuellement actives et s'engagent dans leur première union.

\section{Acknowledgments}

The authors thank Paul Stupp and his team at the Centers for Disease Control and Prevention for assistance in locating and utilizing many of the data sets used in this study, as well as Janine Barden-O'Fallon and Chirayath Suchindran for help with the analyses.

Author contact:samandar@email.unc.edu 